\title{
Transit Service, Parking Charges, and Mode Choice for the Journey to Work: An Analysis of the 1990 NPTS
}

\author{
James G. Strathman \\ Kenneth J. Dueker \\ Portland State University
}

\begin{abstract}
In this paper, the effects of transit service and parking charges on the choice of commuters to drive alone, carpool, or use transit are estimated. The analysis is based on dat a for 20 Consolidated Metropolitan Statistical Areas from the 1990 Nationwide Personal Transportation Survey, FTA's Section 15, and the Texas Transportation Institute's estimates of traffic congestion. Both the level of transit service and the likelihood of being charged for parking are found to have significant positive effects on the likelihood of choosing transit for the commute. The results also indicate that improving transit access leads to a very small increase in transit's mode share, while improving the level of service produces a much greater mode share increase.
\end{abstract}

\section{Introduction}

Public transit's importance as a commuting option has steadily declined in recent years. The 1990 Census found that transit serves only 5.1 percent of all 
commuters, down nearly 60 percent from 1960 (Rossetti and Eversole 1993). Carpooling has also not fared well, with the share of commuters choosing this mode falling 32 percent between 1980 and 1990 alone (Rossetti and Eversole 1993). One consequence of these changes is a disproportionate increase over time in the number of vehicle trips required to transport the nation's work force to their work places, with corresponding negative implications for congestion and air quality management (Pisarski 1992). Thus, reducing single occupant vehicle (SOV) commuting has become an increasingly prominent urban transportation policy objective in the 1990s. The regulation and pricing of parking have the potential to make a large contribution to this objective (Kain 1994; Shoup 1994).

This paper analyzes the effects of transit service and the pricing of parking on commuters' mode choices. The data employed in the analysis cover commuters from 20 large metropolitan areas who were interviewed for the 1990 Nationwide Personal Transportation Survey (NPTS). These data are enriched by transit level of service information from the Federal Transit Administration's $1990 \mathrm{Sec}$ tion 15 Report (U.S. Department of Transportation 1991), and congestion estimates from the Texas Transportation Institute (TTI) (Schrank et al. 1993).

\section{Effects of Parking Costs on Commuting}

While many factors affect mode choice for the journey to work, the value of employer-paid parking is so substantial that it "invites commuters to drive to work alone" (Shoup 1982: 352). For commuters to downtown Los Angeles, for example, the estimated value of free parking by itself exceeds all other variable costs of driving by more than 35 percent (Willson and Shoup 1990).

If employer-paid parking is a major cause of SOV commuting, market pricing of parking ought to be considered in attempts to address congestion and air quality problems. But as Segelhorst and Kirkus (1973) noted, rather than impose taxes to compel commuters to take these externalities into account, we instead extend a subsidy to drive alone and make congestion problems even worse. Thus, Kain (1994) suggests that the elimination of employer-paid parking should precede consideration of congestion pricing, and that scrapping parking subsidies 
might in many instances mitigate the need for congestion pricing. Downs (1992) favors market-priced parking over congestion pricing because it can be more easily administered and it does not pose as much a threat to privacy.

Research on the effect that parking prices have on mode choice for the journey to work has been expanding rapidly. This research can be divided into two general categories. The first consists of experimental design-type case studies, whose purposes include 1) documenting changes in mode or utilization following a price increase at selected parking facilities (Kunze et al. 1980; May 1973); 2) estimating changes in mode and parking utilization following a change in parking prices at specific work sites (Miller and Everett 1982; Surber et al. 1984); and 3) assessing differences in commute mode for similarly situated work sites, where one employer provides free or subsidized parking and the other does not (Mehranian et al. 1987; Pickrell and Shoup 1980). The second general category consists of studies that use disaggregate mode choice models, in which the cost of parking is specified as one of the choice attributes (Ben-Akiva and Atherton 1977; Brown 1972; Ganek and Saulino 1976; Gillen 1977; Miller 1993; Ricklin et al. 1994; Willson 1992).

Since excellent reviews of this research already exist, we will not discuss the studies here.' Several issues do deserve comment, however. First, although the case studies attempt to control for or assess spillover parking (i.e., following a price increase, the diversion of previous users of a facility to on-street parking or other facilities), it is not clear that they have been entirely successful. This is evidenced by the greater responses commonly observed in these studies compared to disaggregate choice studies. Second, the case studies commonly find that individuals who shift away from SOV commuting are more likely to become carpoolers than transit riders, while the disaggregate mode choice studies typically estimate the reverse. This may be due to direct promotion of carpooling as a substitute for SOV commuting in many of the reported case studies. It could also reflect a tendency of case studies to focus on locations outside downtowns where carpooling is more attractive, and a tendency of the data in disaggregate choice models to reflect commuting to downtowns, where transit service is bet- 
ter. More generally, the case studies are very anemic in terms of their representation of non-parking factors that affect mode choice.

A shortcoming shared by both the disaggregate choice models and the case studies is their limited treatment of transit and carpool service quality attributes. This is more understandable in the case studies because it would be extremely difficult to set up the analysis so that attributes of transit and carpooling could be systematically varied.?

While the disaggregate mode choice studies are more firmly linked to travel behavior theory, they are not without problems. In contrast to the case study approach, mode choice models may underestimate the parking price elasticity of demand for SOV commuting for several reasons. First, parking costs are frequently expressed as a component of vehicle operating costs, which implies that commuters evaluate the unit costs of parking and other operating outlays equivalently. But Gillen (1977) found that commuters' mode choices were significantly more responsive to unit parking costs, indicating that these costs should be specified separately. Second, efforts to represent parking costs in mode choice models face serious measurement problems. When auto commuters are asked in surveys whether and how much they pay for parking, for example, their responses do not reflect variations in the parking services they consume. Thus, a worker who pays $\$ 100$ per month for a secure on-site space is not necessarily worse off than a coworker who pays less (or nothing) to park blocks away. More troublesome, in virtually all travel surveys parking cost information is not recovered from people who commute by modes other than auto. To estimate mode choices of this group, analysts must first determine how much they would pay for parking if they were to drive. Non-auto commuters could be asked how much they would have to pay for parking in travel surveys, although the reliability of their responses would be unknown. An alternative would be to survey parking facilities in the few Traffic Analysis Zones where pricing exists. Prevailing parking costs could then be applied to all commutes to that zone. Moreover, if both the surveyed work places and the surveyed parking charges are geocoded, the two could be directly linked and measurement error from within zone variation of parking costs greatly reduced. 
Lastly, however precisely parking prices are measured at work destinations, they will not accurately reflect on mode choice decisions when employers pay them. The Tax Reform Act of 1986 added a special rule for parking to the Internal Revenue Code, defining employer-paid parking as a "working condition fringe benefit." Ironically, because commuters cannot deduct parking costs as a workrelated expense (a qualification that applies to other working condition fringes) employer-paid parking is worth considerably more than its face value to them. Employers thus have a strong incentive to substitute free or subsidized parking for higher wages. The employer's incentive is greater for workers in higher marginal tax brackets who, in turn, are also more likely to work where parking charges exist. Peat Marwick (1990) estimated that the value of employer parking subsidies exceeds $\$ 50$ billion per year, indicating that the gap between posted parking prices and the amounts many auto commuters actually pay is substantial.

Willson's (1992) study of commuters to downtown Los Angeles probably represents the most thorough attempt to deal with the problems noted above. Willson assembled parking data from three sources. First, from a household travel survey he recovered the parking costs auto commuters reported paying. For nonauto commuters he determined from their employers whether free parking was provided for everyone. In the cases where employers did not provide free parking, he used information from a survey on the posted parking prices in the sub areas of downtown Los Angeles where these people worked.

\section{Data Description}

The NPTS provides the primary source of data for this study. This periodic survey is the only source of information on travel for all purposes in the U.S. The 1990 survey included nearly 50,000 individuals comprising 22,000 households. In addition to travel activity the survey recovered information on household socioeconomic characteristics and on residential location. Among the locational data is the Consolidated Metropolitan Statistical Area (CMSA) identity of the place of residence. CMSA identification allows NPTS trip and household records to be linked to FTA Section 15 transit service data and TTI congestion estimates. 
Given the focus on commuting, households from the 20 CMSAs who reported making work trips during the survey period were first selected. Commutes, represented by trip chains, were then formed by linking the sequence of trips connecting each worker's residence and work place. ${ }^{3}$ These trip chains can be characterized as either simple, in which the commute is composed of single work trips connecting the residence and place of work, or complex, in which the journey-to-work, time-at-work, or journey-to-home segments contains both work and non-work trips. An example of a complex commute chain would be a worker who first drops a child off at a day care center (the journey to which is classified as a non-work trip), then proceeds to work (a work trip), meets a friend for lunch (a non-work trip) and, at the end of the work day stops again at the day care center (a non-work trip), and finally returns home (a work trip).

Section 15 transit service data for the $20 \mathrm{CMSAs}$, specifically revenue hours of service per capita, were then added. Finally, TTI estimates of the per capita costs of congestion were included. ${ }^{4}$ Congestion cost estimates were available for each of the CMSAs except Buffalo and Providence. For commuters from these two CMSAs, which account for one percent of the observations in the data base, TTI's respective regional estimates of per capita congestion costs were used.

The data base consists of 3,645 observations, or round-trip commutes. Some of the salient characteristics of these commutes, the transit service environment, and congestion conditions are shown in Table $1 .{ }^{5}$ The first data column in the table reports the number of observations for each CMSA. More than half of the CMSAs have fewer than 100 observations, indicating that the NPTS metropoli$\tan$ level statistics in the table may not be very precise. ${ }^{6}$ Over all CMSAs, however, the NPTS variables in the table do provide a fairly representative picture of U.S. metropolitan commuting activity.

Regarding the NPTS variables in Table 1, more than one-third of the commutes include trip-making beyond direct travel between home and work. The SOV mode accounts for 75 percent of commutes, while carpools and transit account for 13 and 8 percent, respectively, and other modes (mainly walking) make up the remainder. Auto commuters were asked if they paid for parking at work, 
and only 5 percent indicated that they did, a substantial decline from the near 15 percent who reported doing so in a roughly comparable 1965 survey (Lansing and Hendricks 1967).

Table 1

Selected Commuting Characteristics in the 1990 NPTS-Section 15-TTI Sample

\begin{tabular}{|c|c|c|c|c|c|c|c|c|c|c|}
\hline \multirow[b]{2}{*}{$C M S A$} & \multirow[b]{2}{*}{$N$} & \multirow[b]{2}{*}{$\begin{array}{c}\text { Complex } \\
\text { Com- } \\
\text { mutes }\end{array}$} & \multicolumn{4}{|c|}{ Travel Mode } & \multicolumn{3}{|c|}{ Transit Service } & \multirow{2}{*}{$\begin{array}{l}\text { Per } \\
\text { Cap. } \\
\text { Con- } \\
\text { gest. }\end{array}$} \\
\hline & & & sov & $\begin{array}{l}\text { Car- } \\
\text { Pool }\end{array}$ & $\begin{array}{c}\text { Mass } \\
\text { Tran- } \\
\text { sit }\end{array}$ & Other & $\begin{array}{c}\text { Pay } \\
\text { to } \\
\text { Park }\end{array}$ & $\begin{array}{c}\text { Access } \\
(I / 4 \\
\text { mi.) }\end{array}$ & $\begin{array}{l}\text { Per } \\
\text { Cap. } \\
\text { Hrs. }\end{array}$ & \\
\hline Boston & 97 & $42.3 \%$ & $72.2 \%$ & $11.3 \%$ & $6.2 \%$ & $10.3 \%$ & $6.6 \%$ & $46.4 \%$ & 1.45 & $\$ 490$ \\
\hline Buffalo & 24 & 41.7 & 75.0 & 25.0 & 0.0 & 0.0 & 4.5 & 58.3 & .99 & 380 \\
\hline Chicago & 255 & 38.4 & 74.9 & 13.7 & 8.2 & 3.1 & 4.1 & 47.1 & 1.81 & 300 \\
\hline Cincinnati & 81 & 29.6 & 86.4 & 11.1 & 0.0 & 2.5 & 5.2 & 32.1 & .82 & 160 \\
\hline Cleveland & 91 & 30.8 & 81.3 & 12.1 & 3.3 & 3.3 & 7.2 & 30.8 & 1.10 & 120 \\
\hline Dallas & 138 & 47.8 & 84.8 & 14.5 & 0.7 & 0.0 & 6.1 & 30.4 & .73 & 570 \\
\hline Denver & 78 & 33.3 & 85.9 & 7.7 & 5.1 & 1.3 & 5.8 & 53.8 & 1.07 & 370 \\
\hline Detroit & 151 & 37.1 & 89.4 & 9.3 & 0.7 & 0.7 & 4.9 & 21.2 & .67 & 380 \\
\hline Hartford & 269 & 37.2 & 84.0 & 9.7 & 2.2 & 4.1 & 2.5 & 28.3 & 1.19 & 220 \\
\hline Houston & 132 & 38.6 & 89.4 & 7.6 & 1.5 & 1.5 & 6.6 & 25.8 & .84 & 570 \\
\hline Los Angeles & 447 & 39.6 & 77.9 & 16.3 & 2.7 & 3.1 & 3.4 & 49.9 & .92 & 670 \\
\hline Miami & 74 & 36.5 & 71.6 & 25.7 & 2.7 & 0.0 & 1.4 & 43.2 & 1.31 & 520 \\
\hline Milwaukee & 61 & 27.9 & 77.0 & 13.1 & 3.3 & 6.6 & 13.7 & 26.2 & 1.51 & 160 \\
\hline New York & 1152 & 34.6 & 64.2 & 12.1 & 15.9 & 7.8 & 5.5 & 46.0 & 2.74 & 390 \\
\hline Philadelphia & 194 & 36.6 & 72.7 & 13.4 & 7.7 & 6.2 & 4.4 & 39.7 & 1.40 & 270 \\
\hline Pittsburgh & 79 & 35.4 & 67.1 & 22.8 & 5.1 & 5.1 & 7.6 & 36.7 & 1.96 & 270 \\
\hline Portland & 44 & 31.8 & 81.8 & 15.9 & 2.3 & 0.0 & 7.7 & 50.0 & 1.35 & 330 \\
\hline Providence & 27 & 37.0 & 74.1 & II.I & 7.4 & 7.4 & 4.8 & 37.0 & .56 & 380 \\
\hline San Fran. & 153 & 41.8 & 80.4 & 9.2 & 5.9 & 4.6 & 4.6 & 60.1 & 2.13 & 760 \\
\hline Seattle & 98 & 39.8 & 78.6 & 15.3 & 2.0 & 4.1 & 5.7 & 53.1 & 1.31 & 660 \\
\hline Overall & 3645 & 36.9 & 74.7 & 12.9 & 7.6 & 4.8 & 5.0 & 42.3 & 1.71 & 420 \\
\hline
\end{tabular}


Over 40 percent of the sample resides within $1 / 4$ mile of transit service, a distance that transit planners generally consider "accessible." Transit service averages 1.7 revenue hours per urban area resident. Not surprisingly, the older, more densely developed eastern metropolitan areas generally provide higher levels of transit service, while service levels in the southern and western metropolitan areas are lower. This pattern is not universal; San Francisco and Portland offer fairly high levels of service, while Detroit and Providence provide comparatively less than their regional counterparts. Ignoring the polar cases of New York and Providence, the range of transit service provided in these CMSAs is noteworthy. San Francisco's transit service ( 2.13 hours per capita) is more than three times the level supplied in Detroit.

The TTI estimates indicate that the annual costs of congestion average $\$ 420$ per resident. The most noteworthy pattern among the 20 CMSAs is an inverse association of congestion costs and transit service. Metropolitan areas with higher congestion costs per capita-Seattle, Los Angeles, Houston, and Dallas, for example-tend to provide relatively lower levels of transit service. Alternatively, metropolitan areas with relatively high levels of transit service, such as Chicago, Milwaukee, New York, and Pittsburgh, tend to have lower congestion costs. In contrast, however, are San Francisco and Boston, where relatively high congestion costs occur with high levels of transit service, and Buffalo, Cincinnati, Detroit, and Providence, where both congestion costs and transit service levels are relatively low. These two "deviant" groups may reflect the pressures of accelerated growth on the transportation infrastructure of the former, and the consequences of economic maturity or decline for the latters' transportation systems.

\section{Model Specification}

As discussed earlier, the first step in estimating a mode choice model containing parking costs is to reconcile the "missing data" problem for non-auto commuters. Thus, we begin by estimating the probability that auto commuters will pay for parking at work as a function of various characteristics, and then use the parameters of this model to predict the probability of parking charges for everyone else. The purpose here is to recover an instrumental estimate of the 
likelihood that each commuter would have to pay for parking that is independent of his or her reported mode. Consistent with an approach employed by Cambridge Systematics (1990), a binary logit model is estimated in which the probability of being charged for parking at work is related to auto commuters' age and income, work trip distance, and several urban and locational characteristics. The model is specified as follows:

where

$$
\log \left(\mathrm{P}_{\mathrm{p}} / 1-\mathrm{P}_{\mathrm{p}}\right)=\mathrm{f}(\mathrm{POP}, \mathrm{WTD}, \mathrm{DEN}, \mathrm{Y}, \mathrm{A})
$$

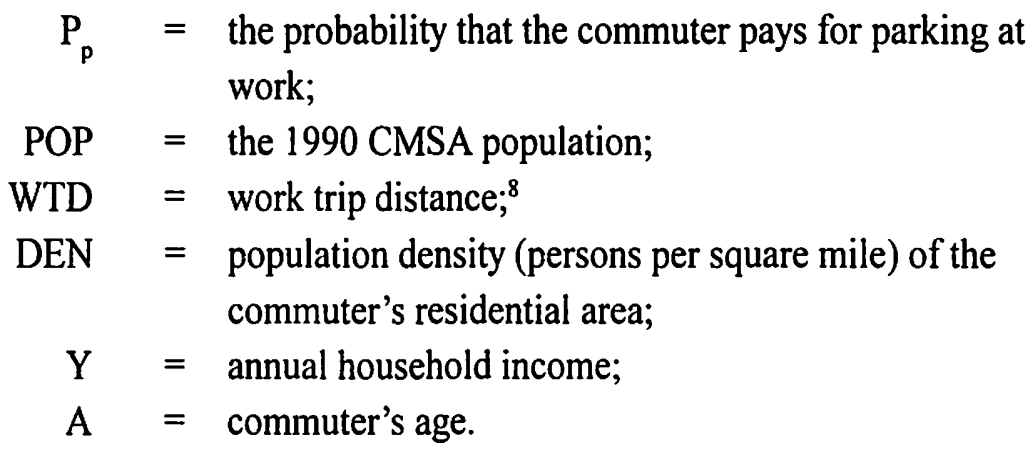

As the parking studies cited earlier have found, persons who must pay for parking at work are more likely to commute by transit or carpools than those who park free. The likelihood that a given worker will pay for parking, in turn, can be characterized as a function of his or her work place location. Work place location is important because parking charges are commonly observed only where the opportunity cost of the land devoted to parking is high, in other words, in the Central Business District (CBD).

Unfortunately, the NPTS does not identify work place location. As a result, several other locational proxies are included in the parking price probability model. The first proxy is the CMSA population. It is hypothesized that the pay-to-park probability will be inversely related to this variable, reflecting the fact that the CBD's share of total employment is smaller in larger metropolitan areas. Second, we have included the density of the worker's residential area, and hypothesize that it is directly related to the likelihood of work place parking charges. This 
hypothesis is based on the evidence that workers live in high density areas to be more accessible to their work places (Rossetti and Eversole 1993), and that work places in higher density areas are more likely to charge for parking. We have also included the distance of the work trip because longer commutes are more likely to be destined for the CBD (Giuliano and Small 1992). Income is included to reflect the urban wage gradient's maximum in the CBD. Finally, the worker's age is included as a crude surrogate for job tenure, which is hypothesized to be greater for CBD workers.

Given the instrumental estimate of the probability of paying for parking for all commuters in the sample, a multinomial logit model is then specified to estimate the relative probabilities of driving alone, carpooling and transit as a function of various personal, household, locational and metropolitan factors. The general specification of the model is as follows:

$$
\log \left(\mathrm{P}_{i} \mathrm{P}_{\mathrm{j}}\right)=\mathrm{f}\left(\mathrm{CC}, \mathrm{D}, \mathrm{TA}, \mathrm{Y}, \mathrm{F}, \mathrm{A}, \mathrm{TRH}, \mathrm{CPC}, \mathrm{S}, \mathrm{E}, \mathrm{S}_{1}, \mathrm{~S}_{2}, \mathrm{MAH}, \mathrm{SAC}, \mathrm{MAC}, \mathrm{E}(\mathrm{PP})\right)
$$

where

$\log \left(\mathrm{P}_{\mathrm{i}} / \mathrm{P}_{\mathrm{j}}\right) \quad=$ the $\log$ of the relative probabilities of selecting modes $\mathrm{i}$ and $\mathrm{j}$;

$\mathrm{CC}=$ complex commute: a dummy variable equaling one if the journey to work consists of a combination of work and non-work trips, zero otherwise;

$\mathrm{D}=$ total home-to-work commute distance (in miles);

$\mathrm{TA}=$ transit access: a dummy variable equaling one if the person resides within $1 / 4$ mile of transit service, zero otherwise;

$\mathrm{Y}=$ annual household income (in thousands);

$\mathrm{F}=$ gender: a dummy variable equaling one if the commuter is female, zero otherwise;

$\mathrm{A}=$ commuter's age;

$\mathrm{TRH}=$ transit revenue hours of service per CMSA resident; 


\section{$\mathrm{CPC}=\mathrm{CMSA}$ congestion costs per capita; \\ $\mathrm{S}=$ residential location: a dummy variable equaling one if the commuter is a suburban resident, zero otherwise; \\ $\mathrm{E}=$ residential location: a dummy variable equaling one if the commuter is an exurban resident, zero otherwise; \\ $\mathrm{S}_{1} \quad=$ city size: a dummy variable equaling one if the 1990 CMSA population is greater than 2.5 million and less than 5.0 million, zero otherwise; \\ $\mathrm{S}_{2} \quad=$ city size: a dummy variable equaling one if the 1990 CMSA population is less than 2.5 million, zero other- wise;}

$\mathrm{MAH}=$ life cycle: a dummy variable equaling one if the commuter's household consists of multiple adults with no dependents, zero otherwise;

$\mathrm{SAC}=$ life cycle: a dummy variable equaling one if the commuter's household consists of a single adult with dependent children, zero otherwise;

MAC = life cycle: a dummy variable equaling one if the commuter's household consists of multiple adults with dependent children, zero otherwise;

$\mathrm{E}(\mathrm{PP})=$ the estimated probability that the commuter would pay for parking at work if he or she commuted by auto.

It is hypothesized that individuals with complex commutes will favor the SOV mode. Activities linked to the commute can be more flexibly scheduled and conveniently accessed by the SOV mode, while the transit and carpool options imply either substantial time or activity choice penalties (Kondo and Kitamura 1987). For example, if the commute includes stops at a pre-school, commuting by transit might limit a person's choice to a program that is directly accessible to his or her place of work, whereas an SOV commute would expand the options. 
Longer commutes tend to enhance the relative attractiveness of transit and carpooling. The waiting or assembly times for these modes are essentially fixed, and thus their share of total travel time declines with increases in commuting distance.

Both access and level of service are posited to have positive effects on the relative attractiveness of transit to commuters. First, residing within walking distance of transit service signals that this service can be conveniently accessed, which enhances the likelihood that it will be chosen (Talvitie 1972). Second, higher service levels tend to shorten headways, which reduces passenger waiting time and lessens transit's relative travel time disadvantage. Lave (1970), for example, estimated that a 10-minute reduction in transit's relative travel time would divert about 7 percent of the Chicago region's commuters to transit.

The opportunity cost of time is known to be a positive function of income. Therefore, higher-income commuters implicitly value travel time at higher levels and have a higher willingness-to-pay for more time-saving modes. All other things being equal, higher-income workers are thus more likely to be SOV commuters.

Historically, women have had a greater tendency to commute by transit and carpools. However, women workers are now just as likely to be licensed to drive as men (Rosenbloom 1994). Also, women accounted for about two-thirds of the 42 million new workers added between 1969 and 1990 (Hu and Young 1993). In turn, the jobs these workers have filled have been concentrated in suburban and exurban locations, where transit has not been a very effective competitor.

The effect of age on the mode choice of commuters has not been very thoroughly researched. The 1990 NPTS shows a commonly observed profile, with workers younger than 20 and older than 60 being relatively less likely to commute by private vehicle (Hu and Young 1993). Since the potentially confounding effects of income and life cycle status are controlled for in the present specification, basic age-related phenomena, such as habit formation or preferences for comfort and convenience, may exert a more discernible effect. 
Congestion affects mode choice by undermining the automobile's travel time advantage over transit (Downs 1962). Clearly, transit (bus in particular) is also negatively affected by congestion, but because transit's in-vehicle times are a smaller component of total travel time, it is penalized relatively less than the auto. While this effect is straightforward in principle, it is important to remember that congestion affects travel in a localized way. The congestion data employed here reflect general traffic conditions in each of the urban areas. The experiences of commuters in each of these areas vary widely, however, and it is the congestion experienced by each commuter that affects his or her mode choice. The TTI index is thus a fairly crude proxy in the context of disaggregate analysis.

One consequence of the decentralization of employment in U.S. metropolitan areas is that the commutes of suburban and exurban residents are now about twice as likely to be destined for suburban and exurban work places as they are for work places in the central city (Gordon et al. 1989). These commutes occur in an environment where both origins and destinations are dispersed and relatively less well-suited to transit. Thus, even in metropolitan areas with frequent transit service and good access to transit on average, suburban residents tend to find that transit service in their areas and to their work places is less attractive.

Gordon et al.'s (1989) analysis of commuting in the 1977 and 1983 NPTS suggests that the most substantial locational realignment of work places and residences occurred in metropolitan areas with more than three million residents, leading them to conclude that "the spatially extensive very large metropolitan areas offer the most opportunities for relocational adjustments to avoid congestion" (pp. 52-53). We have thus included two dummy variables to capture categorical effects of CMSA size.

Household composition and life cycle status have been shown to have important effects on travel activity and mode choice (Strathman et al. 1994). With licensing and automobile availability nearing saturation levels among the adult population, household size and structure also have become key determinants of vehicle occupancy (and thus carpool formation). ${ }^{9}$ Workers in multi-person households are expected to be less likely to commute by transit due to a greater poten- 
tial for either carpooling (in the case of multiple working adults) or increased demands for meeting the needs of non-driving dependents.

The effect of parking on mode choice is defined to be the probability of discrete event rather than a monetary function as in other studies. The NPTS does contain the amount that respondents reported paying for parking, but success in estimating a parking price model with this value as the dependent variable was limited. ${ }^{10}$ Thus, a simpler but better-performing alternative was adopted.

The mode choice specification is fairly rich in its representation of the commuter's personal and household characteristics, but it is also noticeably weak in its characterization of transportation system elements and other important factors (such as relative travel times and costs, and work place location). While it would be desirable to have these system variables in the model, their absence does not necessarily undermine the analysis. Talvitie (1972), for example, tested a variety of alternative mode choice specifications and found that a model containing commuter characteristics and only one system variable (walk access to transit) performed as well as a model in which system attributes were fully represented.

\section{Results}

The pay-to-park probability model was estimated for the subset of nearly 3,200 automobile commuters, and the results are presented in Table 2. The model estimates that the likelihood of parking charges is positively related to household income and residential density, and negatively related to metropolitan size. The coefficients for commute distance and age have the expected signs, but are not statistically significant.

Aside from the likelihood ratio statistic, one way of assessing the parking probability model is to determine whether its probability estimates differ in a meaningful way for auto and transit commuters. If parking costs are the single most important reason why downtown commuters choose transit, as Willson (1991) reported, one would expect that the parking charge probabilities calculated for "out-of-sample" transit riders would be higher than the estimated probabilities for "in-sample" auto commuters. This difference is evident and statisti- 
cally significant: transit users are estimated to be nearly 60 percent more likely than auto commuters to face parking charges at work (i.e., .073 versus .046). By comparison, a national travel survey in 1965 determined that transit riders were more than 30 percent more likely to face parking charges at work than auto commuters (Lansing and Hendricks 1967),

Parameter estimates for the mode choice model are presented in Table 3. The coefficients for both of the transit variables and the parking probability variable are consistent with their hypothesized effects and are statistically significant." "The likelihood of choosing either transit or carpooling over SOV is significantly greater for workers who reside within one-quarter of a mile of transit service

\section{Table 2}

Logit Model Parameter Estimates of the Probability That

Auto Commuters Will Pay for Parking

(Asymptotic $t$ values in parentheses)

Variable

Intercept

Parameter Estimate

CMSA Population $-.03826$

Work Trip Distance .00401

Residence Area Pop. Density .00004

Household Income .00002

Commuter's Age .00497

Log Likelihood Function (0) $-593.0$

Log Likelihood Function (b)

Likelihood Ratio Statistic

$\mathrm{N}$

3193

* Significant at the .05 level.

than those who do not. Greater transit access does not significantly alter the relative likelihood of choosing transit over carpooling. Independent of transit access, increasing the level of transit service significantly enhances the likelihood that transit will be chosen over both SOV and carpooling. Workers with a higher. probability of having to pay for parking are significantly less likely to drive alone, and transit is estimated to gain relative to carpooling from the consequent diversion of SOV commuters. 


\section{Table 3}

Multinomial Logit Estimates of Commute Mode Choice Model Coefficients (Asymptotic t values in parentheses)

\begin{tabular}{|c|c|c|c|}
\hline \multirow[t]{2}{*}{ Variable } & \multicolumn{3}{|c|}{ Dependent Variables* } \\
\hline & $\log \left(P_{c} / P_{d}\right)$ & $\log \left(P_{t} / P_{d}\right)$ & $\log \left(P_{t} / P_{c}\right)$ \\
\hline \multirow{2}{*}{ Intercept } & -2.002 & -2.962 & -.960 \\
\hline & $(-4.38)^{* *}$ & $(-4.45)^{* *}$ & $(-1.28)$ \\
\hline \multirow[t]{2}{*}{ Complex Commute $(1,0)$} & -.045 & -.319 & -.273 \\
\hline & $(-.40)$ & $(-1.60)$ & $(-1.26)$ \\
\hline \multirow[t]{2}{*}{ Commute Distance } & .007 & .020 & .012 \\
\hline & $(1.73)$ & $(3.37)^{* *}$ & $(2.21)^{* *}$ \\
\hline \multirow[t]{2}{*}{ Transit Access within $1 / 4$ Mile $(1,0)$} & .323 & .574 & .250 \\
\hline & $(2.71)^{* *}$ & $(2.79)^{* *}$ & $(1.10)$ \\
\hline \multirow[t]{2}{*}{ Household Income } & -.017 & -.038 & -.021 \\
\hline & $(-5.42)^{* *}$ & $(-7.80)^{* *}$ & $(-4.01)^{* *}$ \\
\hline \multirow[t]{2}{*}{ Female Commuter $(1,0)$} & .372 & .262 & -.109 \\
\hline & $(3.33)^{* *}$ & $(1.60)$ & $(-.59)$ \\
\hline \multirow[t]{2}{*}{ Age } & -.012 & -.028 & -.015 \\
\hline & $(-3.19)^{* *}$ & $(-4.33)^{* *}$ & $(-2.27)^{* *}$ \\
\hline \multirow[t]{2}{*}{ CMSA Transit Revenue Hours per Capita } & .105 & .989 & .883 \\
\hline & $(1.15)$ & $(6.31)^{* *}$ & $(5.18)^{* *}$ \\
\hline \multirow[t]{2}{*}{ CMSA Congestion Costs per Capita } & .0003 & -.001 & -.001 \\
\hline & $(.56)$ & $(-1.56)$ & $(-1.72)$ \\
\hline \multirow[t]{2}{*}{ Suburban Resident $(1,0)$} & -.497 & -.925 & -.428 \\
\hline & $(-4.04)^{* *}$ & $(-4.55)^{* *}$ & $(-1.88)$ \\
\hline \multirow[t]{2}{*}{ Exurban Resident $(1,0)$} & -.140 & -1.907 & -1.767 \\
\hline & $(-.78)$ & $(-2.70)^{* *}$ & $(-2.42)^{* *}$ \\
\hline \multirow[t]{2}{*}{ CMSA Pop. Equals $2.5-5.0$ Mil. $(1,0)$} & -.405 & -.366 & .039 \\
\hline & $(-2.49)^{* *}$ & $(-1.38)$ & $(.13)$ \\
\hline \multirow[t]{2}{*}{ CMSA Pop. Less Than 2.5 Mil. $(1,0)$} & -.133 & -.608 & -.475 \\
\hline & $(-.79)$ & $(-1.71)$ & $(-1.27)$ \\
\hline \multirow[t]{2}{*}{ Multiple Adult Household $(1,0)$} & .910 & .445 & -.466 \\
\hline & $(3.37)^{* *}$ & $(1.65)$ & $(-1.33)$ \\
\hline \multirow[t]{2}{*}{ Single Adult with Child(ren) $(1,0)$} & 1.109 & .011 & -1.098 \\
\hline & $(3.08)^{* *}$ & $(.02)$ & $(-2.27)^{* *}$ \\
\hline \multirow[t]{2}{*}{ Multiple Adults with Child(ren) $(1,0)$} & 1.117 & .385 & -.733 \\
\hline & $(4.08)^{* *}$ & $(1.35)$ & $(-2.01)^{* *}$ \\
\hline \multirow[t]{2}{*}{ Pay-to-Park Probability } & 5.699 & 30.253 & 24.554 \\
\hline & $(1.98)^{* *}$ & $(10.89)^{* *}$ & $(8.05)^{* *}$ \\
\hline \multirow{2}{*}{\multicolumn{2}{|c|}{$\begin{array}{ll}\text { Log Likelihood Function (0): } & -2293.1 \\
\text { Log Likelihood Function (B): } & -1925.1\end{array}$}} & & \\
\hline & $\mathrm{n}:$ & 3469 & \\
\hline \multicolumn{4}{|c|}{ * $P_{t} P_{d}$ and $P_{t}$ are the probabilities of carpool, drive alone and transit choice. } \\
\hline
\end{tabular}


Commuters with complex trip chains are estimated to be more likely to drive alone, although the effect is not statistically significant. This may reflect the efforts taken to ensure that walk trips were fully represented in the NPTS. Because walk trips are usually under-reported in travel surveys, there is a greater tendency for transit commuters to report simple chains. It has been reported (Lawton 1995) that when walk trips are fully represented transit commuters are as likely to have complex trip chains as auto commuters. Alternatively, it may be that trip-chaining considerations are secondary to transit service level/quality considerations in mode choice decisions.

Commute distance has a positive effect on the relative probabilities of choosing transit over SOV and carpooling, and no effect on the relative probabilities of SOV and carpool choice. Increases in household income reduce the likelihood of choosing transit over both SOV and carpools, and diminish the likelihood of carpooling relative to SOV commuting. The only significant effect associated with gender is the relatively greater likelihood that women will choose to carpool over driving alone. Older commuters are relatively less likely to choose carpooling or transit over SOV commuting, and they also find transit less attractive than carpooling.

Generally, higher levels of congestion are estimated to be unrelated to individual mode choice decisions. As discussed earlier, this may simply indicate the gross nature of the proxy in this context. Compared with central city residents, suburbanites and exurbanites are progressively less likely to choose transit over carpooling and SOV commuting. Suburban residents are also relatively less likely than their central city counterparts to favor carpooling over SOV. This latter distinction does not extend to exurbanites, however. The only significant finding with respect to metropolitan size is that commuters in urban areas with 2.5 to 5.0 million residents are less likely to choose carpooling over SOV than commuters in areas with more than 5.0 million residents.

Household structure is estimated to have significant effects on mode choice. Compared to single workers, households composed of multiple adults, single adults with children, and multiple adults with children are progressively more likely to choose carpooling over SOV commuting. In addition, households com- 
posed of multiple adults with children and single adults with children are progressively less likely to choose transit over carpooling than are single worker households.

Table 4 presents predicted mode shares for prescribed levels of the three attributes this paper is mainly concerned with, namely transit access, transit revenue hours per capita, and the probability of paying for parking. The attribute levels chosen are well within the range of observed values in the data. For each of these attribute levels, the mode choice probabilities were predicted for each commuter. A weighted average probability was then calculated, using the NPTS

\begin{tabular}{|c|c|c|c|}
\hline \multicolumn{4}{|c|}{$\begin{array}{c}\text { Table } 4 \\
\text { Predicted Mode Shares for } \\
\text { Alternative Levels of Transit Access, } \\
\text { Transit Service, and } \\
\text { “Pay-to-Park” Probability } \\
\text { Modal Shares }\end{array}$} \\
\hline $\begin{array}{c}\text { Attributed } \\
\text { Level }\end{array}$ & sov & Carpool & Transit \\
\hline \multicolumn{4}{|c|}{ 1/4 mi Transit Access (\%) } \\
\hline 30 & .785 & .129 & .086 \\
\hline 40 & .781 & .130 & .089 \\
\hline 50 & .778 & .131 & .091 \\
\hline 60 & .775 & .132 & .093 \\
\hline \multicolumn{4}{|c|}{ Revenue Hrs Per Capita } \\
\hline .75 & .806 & .141 & .053 \\
\hline 1.00 & .800 & .138 & .062 \\
\hline 1.25 & .792 & .135 & .073 \\
\hline 1.50 & .782 & .132 & .086 \\
\hline 1.75 & .772 & .128 & .100 \\
\hline 2.00 & .760 & .125 & .115 \\
\hline \multicolumn{4}{|c|}{ Pay-to-Park Probability } \\
\hline .01 & .816 & .138 & .046 \\
\hline .05 & .771 & .131 & .098 \\
\hline .10 & .674 & .121 & .205 \\
\hline .15 & .544 & .119 & .337 \\
\hline
\end{tabular}
person weights. Thus, the predictions in Table 4 are representative of U.S. metropolitan commuters.

While most of the estimated parameters associated with the three transit and parking attributes are statistically significant, it is clear from Table 4 that there are marked differences in their predicted mode share effects. For instance, changes in transit access have a very small effect on the shares, while increases in the level of transit service and the pay-to-park probability have fairly substantial effects. An increase in transit revenue hours per capita from 1.0 to 2.0 , for example, is predicted to increase transit's share from 6 to more than 11 percent, and a doubling of the pay-to-park probability from .05 to .10 is predicted to boost transit's share by 110 percent. Transit's 6 percentage point share gain from the revenue hour 
increase is predicted to come at the expense of reductions of 2 and 4 percentage points in the shares of carpooling and SOV. Alternatively, its gain from increasing the pay-to-park probability comes almost entirely from an SOV share reduction.

While the parking-related changes in shares for transit and SOV are consistent with outcomes of other studies, the slight decline in carpooling associated with increasing the likelihood of charging for parking is not. Willson (1992), for example, estimated that an increase in parking costs from $\$ 3$ to $\$ 6$ per day would result in a 3 percentage point increase in carpooling's share.

It is important to recognize issues that condition interpretation of these findings. It should be emphasized that the relationship between the level of transit service and the likelihood of choosing transit is not unilateral. Clearly, while one can expect that improving transit service will lead to more riders, it is also known that transit planners consider ridership in making service changes. Thus, increases in transit use can lead to more service. This simultaneity has been analyzed by Peng et al. (1995). Also, as discussed earlier, an ideal parking probability instrument would be estimated from factors that influence the likelihood of being charged for parking but are yet unrelated to mode choice decisions. In reality, however, we know that there is considerable confounding of factors linked to parking conditions and transit use.

\section{Conclusions}

Our analysis indicates that there is an opportunity for increasing transit utilization and reducing SOV commuting. This opportunity can be realized by increasing the level of transit service and ensuring that a larger share of commuters face parking charges if they decide to drive. Along with this opportunity, however, is a challenge facing transit represented by several less favorable tendencies and conditions.

As the mode share predictions show, making transit more accessible to metropolitan commuters will lead to a much smaller gain in utilization than would increasing the frequency of service provided within existing systems. This is not 
surprising, given that one would expect transit service to be initially concentrated in high density corridors containing commuters who live there in part because they prefer transit. Given limited resources, transit decisionmakers must make trade-offs between coverage and frequency of service. Our analysis suggests that decisionmakers seeking to maximize ridership should make frequency improvements. However, the evidence is that transit decisionmakers have tended to extend service at the expense of increasing frequency (Sale and Green 1979).

Commuter parking charges are only feasible in settings where parking supply is constrained, namely in CBDs. Elsewhere, minimum parking requirements in local zoning ordinances have produced a ubiquitous supply of spaces whose market price is effectively zero (Shoup 1995). Fortunately, the highest quality service provided by most transit systems is to the CBD, and our analysis indicates that market pricing of parking there would effectively reduce SOV commuting. But market pricing alone is not likely to be feasible. Given that the incidence of such pricing would be so narrowly focused on downtowns, this would have the effect of promoting urban fringe development and paradoxically leading to greater rather than less SOV commuting (see Hamerslag et al. 1995). Thus, the most effective long-run strategy would be a transition to market pricing of parking in areas of intense development (e.g., the CBD and special generators like edge cities, hospitals, universities, and airports) combined with immediate reductions in minimum parking requirements elsewhere.

\section{Acknowledgments}

The authors gratefully acknowledge the assistance of Zhen Liu and Zhongren Peng, and the comments of Martha Bianco, Gerard Mildner, Randall Pozdena, Anthony Rufolo, Donald Shoup, and two referees. Research support was provided by the Transit Cooperative Research Program, which is sponsored by the Federal Transit Administration and administered by the Transportation Research Board, National Research Council.

\section{Notes}

1 See Feeney (1989) for a review of the research using disaggregate choice models, and Willson and Shoup (1990), Shoup and Willson (1992), Shoup (1992), Willson (1995), and Shoup (1995) for a review of the case studies and a more general appraisal of the 
causes and consequences of employer-paid parking and parking requirements contained in zoning ordinances.

2 For this reason, a stated preference approach may provide a more fruitful alternative to the before $v$. after and employer-provided $v$. priced studies, because in a stated preference model the levels of key level-of-service attributes can be systematically varied.

3 A more detailed description of the construction of the trip chains is given by Strathman and Dueker (1994).

4 As described by Schrank et al. (1993), these cost estimates cover operating and time losses from recurring and incidental delays.

5 The NPTS file contains both person and household weights so that national level inferences can be made. The values reported in the table for the NPTS variables are in unweighted form, however. It should be noted that because the weights relate to the national level, their application may not yield representative estimates of conditions prevailing in any particular CMSA. New York and Hartford were oversampled, as they participated in a local option program to enrich their data.

- Obviously, some workers in Buffalo walk, bicycle, or use transit, but they weren't among the 24 individuals whose commutes are portrayed in the table. The same applies to Dallas, Miami, and Portland in regard to modes other than auto and transit.

7 For example, see Vincent et al. (1994). New York CMSA observations do have a disproportionate effect on the overall averages, which is most noticeably reflected in the relatively higher share of transit commutes and smaller percentage of commutes involving complex trip chains.

8 This distance measures only the length of the work trip portion of the commute. For commutes that do not involve non-work stops, the work trip distance and the commuting distance specified in the mode choice equation are equivalent. In the case of more complex commutes involving non-work stops, the work trip distance is less than the total commuting distance. Since we expect that complex commuting routines will affect mode choice and that longer commutes are more likely to be complex, it is important to minimize mode-specific confounding effects in specifying the parking charge model.

9 Ferguson's (1994) analysis of carpooling in the 1990 NPTS, for example, shows that the majority of journey-to-work carpools contain members of the same household.

10 NPTS respondents reported the amount paid in various scales (per hour, day, week and month). These values were converted to a monthly equivalent, and we then per- 
formed a Tobit regression of monthly parking costs on the same independent variables defined above in an attempt to estimate an "expected parking price." The poor results obtained may have been due to varying explicit and implicit subsidies that commuters receive from their employers, so that the amount reported represented the respondent's out-of-pocket cost.

"We also explored the possibility of joint effects among the transit and parking probability variables by including interaction terms in initial specifications of the model. Interactive effects of parking price increases and transit service enhancement are considered to be key elements of successful parking demand management programs (e.g., see Williams and Petrait 1993). None of the interaction terms involving transit access, transit revenue hours, and pay-to-park probability were statistically significant, however.

\section{References}

Ben-Akiva, M., and T. J. Atherton. 1977. Choice-Model Predictions of Car-Pool Demand: Methods and Results. Transportation Research Record 637: 13-17.

Brown, G. R. 1972. Analysis of User Preferences for System Characteristics to Cause a Modal Shift. Highway Research Record 417: 25-36.

Cambridge Systematics, Inc. 1994. Interim Report: Home-Based Work Parking Cost Model. Unpublished report. Cambridge, MA: Cambridge Systematics, Inc., 1994.

Downs, A. 1992. Stuck in Traffic: Coping With Peak-Hour Traffic Congestion. Washington, D. C., The Brookings Institution.

Downs, A. 1962. The Law of Peak-Hour Expressway Congestion. Traffic Quarterly: 393409.

Feeney, B. P. 1989. A Review of the Impact of Parking Policy Measures on Travel Demand. Transportation Planning and Technology 13 (1989): 229-244.

Ferguson, E. 1994. Recent Declines in Carpooling. NPTS Special Subject Reports: 1990 Nationwide Personal Transportation Survey. U. S. Department of Transportation, Federal Highway Administration, Office of Highway Information Management, Washington, D. C.

Ganek, J., and R. Saulino. 1976. A Disaggregate Modal-Split Model for Work Trips Involving Three Mode Choices. Transportation Research Record 610: 25-29.

Gillen, D. W. 1977. Estimation and Specification of the Effects of Parking Costs on Urban Transport Mode Choice." Journal of Urban Economics 4: 186-199. 
Gordon, P., A. Kumar, and H. W. Richardson. 1989. Congestion, Changing Metropolitan Structure, and City Size in the United States. International Regional Science Review 12: 45-56.

Giuliano, G., and K. A. Small. 1992. Is the Journey to Work Explained by Urban Structure? Working Paper No. 107, The University of California Transportation Center, University of California at Berkeley.

Hamerslag, R., J. D. Fricker, and P. Van Beek. 1995. Parking Restrictions in Employment Centers: Implications for Public Transport and Land Use. Paper presented at the 74th Annual Meeting of the Transportation Research Board, Washington, D.C.

Hu, P. S., and J. Young. 1992. Summary of Travel Trends: 1990 Nationwide Personal Transportation Survey. U. S. Department of Transportation, Federal Highway Administration, Office of Highway Information Management, Washington, D. C.

Hu, P. S., and J. Young. 1993. 1990 NPTS Databook: Nationwide Personal Transportation Survey, Volume II. U. S. Department of Transportation, Federal Highway Administration, Office of Highway Information Management, Washington, D. C.

Kain, J. 1994. Impacts of Congestion Pricing on Transit and Carpool Demand and Supply. In Transportation Research Board, Curbing Gridlock, Vol. 2. National Research Council, Washington, D. C.: National Academy Press.

Kondo, K., and R. Kitamura. 1987. Time-Space Constraints and the Formation of Trip Chains. Regional Science and Urban Economics 17: 49-65.

Kunze, B., C. Heramb, and T. Martin. 1980. Impacts of Municipal Parking Fee Increases in Downtown Chicago. Transportation Research Record 786: 21-30.

Lansing, J. B., and G. Hendricks. 1967. Automobile Ownership and Residential Density. Report prepared for the Bureau of Public Roads, Federal Highway Administration, U.S. Department of Transportation. Ann Arbor, MI: Survey Research Center, Institute for Social Research, University of Michigan.

Lave, C. A. 1970. The Demand for Urban Mass Transportation. The Review of Economics and Statistics, 52: 320-323.

Lawton, K. 1995. Surveys for Improved Models, A Response to ISTEA and the CAAA requirements. Presentation at the Fifth National Conference on Transportation Planning Methods Applications, Seattle, WA: Transportation Research Board.

May, A. D. 1973. Traffic Management and Restraint by Parking Control in Greater London. Highway Research Record 474: 19-30. 
Mehranian, M., M. Wachs, D. Shoup, and R. Platkin. 1987. Parking Costs and Mode Choices among Downtown Workers: A Case Study. Transportation Research Record 1130: $1-5$.

Miller, E. J. 1993. Central Area Mode Choice and Parking Demand. Transportation Research Record 1413: 60-69.

Miller, G. K., and C. T. Everett. 1982. Raising Commuter Parking Prices-An Empirical Study. Transportation 11: 105-129.

Peat Marwick, Inc. 1990. The Dimensions of Parking. Unpublished study prepared for the U.S. Department of Transportation, Washington, D.C.

Peng, Z., K. J. Dueker, J. Strathman, and J. Hopper. "A Simultaneous Route-Level Transit Patronage Model." Transportation (forthcoming).

Pickrell, D. H., and D. C. Shoup. 1980. Employer-Subsidized Parking and Work-Trip Mode Choice. Transportation Research Record 786: 30-37.

Pisarski, A. E. 1992. Travel Behavior Issues in the 90's. U. S. DOT, Federal Highway Administration, Office of Highway Information Management, Washington, D. C.

Riklin, E. S., D. Vozzolo, P. A. Ehrhardt, and J. Colman. 1994. The Projected Effect of Parking Policies on Transit Ridership in the Hartford, Connecticut, Region. Paper presented at the 73rd Annual Meeting of the Transportation Research Board, Washington, D. C.

Rosenbloom, S. 1994. Travel by Women. In NPTS Special Subject Reports: 1990 Nationwide Personal Transportation Survey. U. S. Department of Transportation, Federal Highway Administration, Office of Highway Information Management, Washington, D. C.

Rossetti, M. A., and B. S. Eversole. 1993. Journey to Work Trends in the United States and Its Major Metropolitan Areas, 1960-1990. U. S. Department of Transportation, Research and Special Programs Administration, John A. Volpe National Transportation Systems Center, Cambridge, MA.

Sale, J. E., and B. Green. 1979. Operating Costs and Performance of American Public Transit Systems. Journal of the American Planning Association 45: 22-27.

Schrank, D. L., S. M. Turner, and T. J. Lomax. 1993. Estimates of Urban Roadway Congestion-1990. Research Report 1131-5, Texas Transportation Institute, Texas A\&M University System, College Station, TX.

Segelhorst, E. W., and L. D. Kirkus. 1973. Parking Bias in Transit Choice. Journal of Transport Economics and Policy 7: 58-70. 
Shoup, D. C. 1982. Cashing Out Free Parking. Transportation Quarterly 36: 351-364.

Shoup, D. C. 1992. Cashing Out Employer-Paid Parking. Report No. FTA-CA-11-003592-1, Washington, D. C.: U. S. Department of Transportation.

Shoup, D. C. 1994. Cashing Out Employer-Paid Parking: A Precedent for Congestion Pricing? In Transportation Research Board, Curbing Gridlock, Vol. 2. National Research Council, Washington, D. C.: National Academy Press.

Shoup, D. C. 1995. An Opportunity to Reduce Minimum Parking Requirements. Journal of the American Planning Association 61: 14-28.

Shoup, D. C., and R. W. Willson. 1992. Employer-Paid Parking: The Problem and Proposed Solutions. Transportation Quarterly 46: 169-192.

Strathman, J. G., K. J. Dueker, and J. S. Davis. 1994. Effects of Household Structure and Selected Travel Characteristics on Trip Chaining." Transportation 21: 23-45.

Strathman, J. G., and K. J. Dueker. 1994. Understanding Trip Chaining. In NPTS Special Subject Reports: 1990 Nationwide Personal Transportation Survey, U. S. DOT, Federal Highway Administration, Office of Highway Information Management, Washington, D. C.

Surber, M., D. Shoup, and M. Wachs. 1984. Effects of Ending Employer-Paid Parking for Solo Drivers. Transportation Research Record 957: 67-71.

Talvitie, A. 1972. Comparison of Probabilistic Modal-Choice Models: Estimation Methods and System Inputs. Highway Research Record 392: 111-120.

U. S. Department of Transportation, Urban Mass Transportation Administration. 1991. Transit Profiles: Agencies in Urbanized Areas Exceeding 200,000 Population. 1990 Section 15 Report, Washington D. C.

Vincent, M. J., M. A. Keyes, and M. Reed. 1994. NPTS Urban Travel Patterns: 1990 Nationwide Personal Transportation Survey. U. S. Department of Transportation, Federal Highway Administration, Office of Highway Information Management, Washington, D. C.

Williams, M. E., and K. L. Petrait. 1993. U-PASS: A Model Transportation Management Program That Works. Transportation Research Record 1404: 73-81.

Willson, R. W. 1991. Employer Parking Subsidies, Mode Choice, and Public Policy. Unpublished Ph.D. dissertation, University of California at Los Angeles.

Willson, R. W. 1992. Estimating the Travel and Parking Demand Effects of EmployerPaid Parking. Regional Science and Urban Economics 22: 133-145. 
Willson, R. W. 1995. Suburban Parking Requirements: A Tacit Policy for Automobile Use and Sprawl. Journal of the American Planning Association 61: 29-42.

Willson, R. W., and D. C. Shoup. 1990. Parking Subsidies and Travel Choices: Assessing the Evidence. Transportation 17: 141-157.

\section{About the Authors}

James K. Strathman is Professor of Urban Studies and Assistant Director of the Center for Urban Studies, School of Urban and Public Affairs, Portland State University, Portland, Oregon. Kenneth J. Dueker is Professor of Urban Studies and Director of the Center for Urban Studies, School of Urban and Public Affairs, Portland State University. 